\title{
Amplification of wet and dry month occurrence over tropical land regions in response to global warming
}

\author{
Benjamin R. Lintner, ${ }^{1}$ Michela Biasutti, ${ }^{2}$ Noah S. Diffenbaugh, ${ }^{3}$ Jung-Eun Lee, ${ }^{4}$ \\ Matthew J. Niznik, ${ }^{1}$ and Kirsten L. Findell ${ }^{5}$ \\ Received 18 January 2012; revised 17 April 2012; accepted 17 April 2012; published 5 June 2012.
}

[1] Quantifying how global warming impacts the spatiotemporal distribution of precipitation represents a key scientific challenge with profound implications for human welfare. Utilizing monthly precipitation data from Coupled Model Intercomparison Project (CMIP3) climate change simulations, the results here show that the occurrence of very dry $(<0.5 \mathrm{~mm} /$ day $)$ and very wet $(>10 \mathrm{~mm} /$ day) months comprises a straightforward, robust metric of anthropogenic warming on tropical land region rainfall. In particular, differencing tropics-wide precipitation frequency histograms for 25 -year periods over the late 21 st and 20 th centuries shows increased late-21st-century occurrence of histogram extremes both in the model ensemble and across individual models. Mechanistically, such differences are consistent with the view of enhanced tropical precipitation spatial gradients. Similar diagnostics are calculated for two 15-year subperiods over 1979-2008 for the CMIP3 models and three observational precipitation products to assess whether the signature of late-21st-century warming has already emerged in response to recent warming. While both the observations and CMIP3 ensemble-mean hint at similar amplification in the warmer (1994-2008) subinterval, the changes are not robust, as substantial differences are evident among the observational products and the intraensemble spread is large. Comparing histograms computed from the warmest and coolest years of the observational period further demonstrates effects of internal variability, notably the El Niño/Southern Oscillation, which appear to oppose the impact of quasi-uniform anthropogenic warming on the wet tail of the monthly precipitation distribution. These results identify the increase of very dry and wet occurrences in monthly precipitation as a potential signature of anthropogenic global warming but also highlight the continuing dominance of internal climate variability on even bulk measures of tropical rainfall.

Citation: Lintner, B. R., M. Biasutti, N. S. Diffenbaugh, J.-E. Lee, M. J. Niznik, and K. L. Findell (2012), Amplification of wet and dry month occurrence over tropical land regions in response to global warming, J. Geophys. Res., 117, D11106, doi:10.1029/2012JD017499.

\section{Introduction}

[2] The spatial and temporal distribution of precipitation has a strong influence on human systems. However, the extent to which the distribution of precipitation may change in a warming climate is currently poorly constrained, especially when considering the wet and dry tails of the

\footnotetext{
${ }^{1}$ Department of Environmental Sciences, Rutgers, State University of New Jersey, New Brunswick, New Jersey, USA.

${ }^{2}$ Lamont-Doherty Earth Observatory, Palisades, New York, USA.

${ }^{3}$ Woods Institute for the Environment, Department of Environmental Earth System Science, Stanford University, Stanford, California, USA.

${ }^{4}$ Jet Propulsion Laboratory, California Institute of Technology, Pasadena, California, USA.

${ }^{5}$ Geophysical Fluid Dynamics Laboratory, Princeton, New Jersey, USA.

Corresponding author: B. R. Lintner, Department of Environmental Sciences, Rutgers, State University of New Jersey, 14 College Farm Rd., New Brunswick, NJ 08901-8551, USA. (lintner@envsci.rutgers.edu)

Copyright 2012 by the American Geophysical Union. 0148-0227/12/2012JD017499
}

precipitation distribution [Intergovernmental Panel on Climate Change, 2007]. Indeed, the complex interplay of dynamics and thermodynamics controlling extreme precipitation makes it unlikely that whatever changes do occur will manifest as a simple shift in the precipitation probability density function (pdf) [Emori and Brown, 2005]. Moreover, a large range of time scales must be considered, especially given the inherent asymmetry of hydroclimatic extremes, e.g., a flood can follow a single rainfall event, while droughts occur over longer time scales.

[3] A number of studies [Emori and Brown, 2005; Held and Soden, 2006; O'Gorman and Schneider, 2009; Allan et al., 2010; Romps, 2011] have developed theoretical guidance for how global warming may affect mean and extreme precipitation behavior. A prevailing view is that the regional redistribution of precipitation, or more precisely precipitation minus evaporation, in response to a warmer troposphere can be understood in terms of wet areas or periods becoming wetter and dry areas or periods becoming 


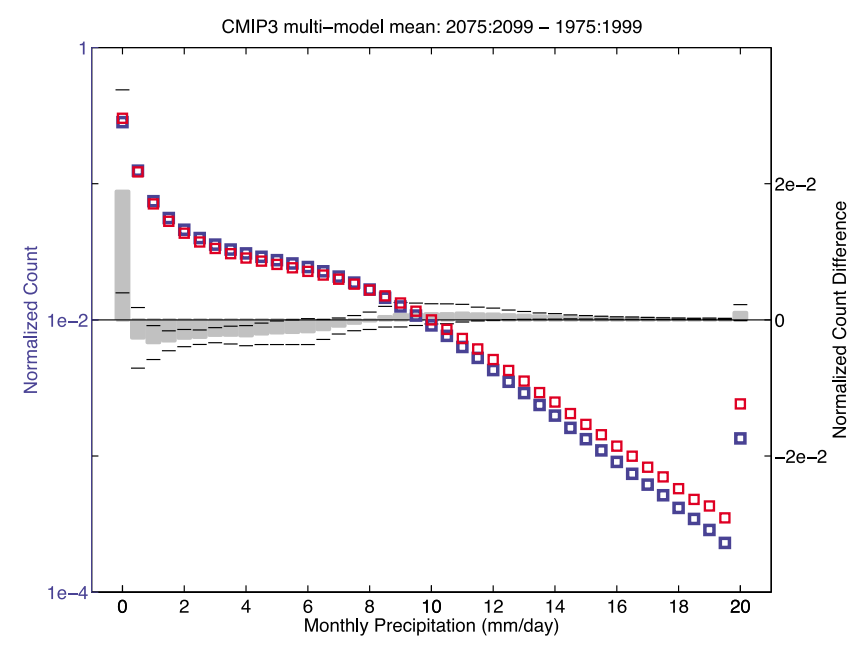

Figure 1. Ensemble-mean CMIP3 precipitation histograms and their difference between the late 20th and 21 st centuries. Shown here are normalized histograms for the ensemble-mean of 24 CMIP3 models for tropical land region (30 S-30 N) monthly mean precipitation counts for the periods January 1975 to December 1999 (1975:1999; blue squares) and January 2075 to December 2099 (2075:2099; red squares), relative to the logarithmic vertical axis on the left, as well as the difference histogram (dark gray bars), relative to the vertical axis on the right). The normalization employed here (and elsewhere, unless otherwise stated) represents the sum over the total histogram. The horizontal dashed lines depict the $\pm 1 \sigma$ levels for the intraensemble variations.

drier [Held and Soden, 2006], although the multiscale nature of precipitation complicates this interpretation. This theoretical argument may be loosely rephrased as predicting that mean precipitation should span a wider distribution, with more extremely dry and wet occurrences. On sufficiently short time scales, extreme rainfall events are also expected to intensify from application of Clausius-Clapeyron (CC) scaling arguments, which predict exponentially increasing water vapor in response to increasing temperature, albeit with deviations away from theoretical scaling because of changes in cloud microphysics, entrainment, and convective velocity profiles [O'Gorman and Schneider, 2009]. At the same time, the upped-ante mechanism [Neelin et al., 2003] predicts that areas that are now marginal for deep convection will become dry in a warmer world, given that a warmer troposphere requires increased moisture to meet a threshold for deep convective occurrence [Neelin et al., 2008] and regions of strong dry air inflow will be unable to achieve the higher threshold. This may help to explain why the frequency of dry days appears to increase with warming [Giorgi et al., 2011].

[4] In summary, there are theoretical reasons to expect that dry and wet "extremes" will be more common across a range of timescales, from daily events to the annual mean climatology, and it is reasonable to expect that similar changes could be expected at the intermediate, monthly time scales. This study focuses on such intermediate timescales: we are motivated here by the idea that changes in the tails of the frequency distribution of monthly rainfall in the global tropics might be more robust than regional changes. Indeed, while some locations exhibit consistency in projected future precipitation change across climate models [Solomon et al., 2009] there is typically large intermodel divergence of rainfall changes on smaller spatial scales [Neelin et al., 2006]. Moreover, from a climate impacts and assessment perspective, knowledge of how monthly rainfall extremes might change is clearly important for applications such as drought and crop-yield forecasting and water resource management.

[5] Here we examine output from 24 global climate models (archived in Phase 3 of the Coupled Model Intercomparison Project (CMIP3) [Meehl et al., 2007]) to quantify changes in the simulated statistics of monthly precipitation that occur in response to anthropogenic global warming (data and methods are given in Section 2). As shown in Section 3, we find a robust projection of increased very dry and very wet monthly counts. We further interpret the histogram changes in terms of a simple model [Lintner and Neelin, 2007, 2008, 2009] describing the transition from weak to strong convection applicable over tropical continents. To compare the strength of the change in the histogram to the noise of internal variability, in Section 4 we perform the same analysis for the same models, as well as the available observations, for the last 30 years. The effect of ENSO, in contrast to the effect of more uniform warming, is explored in more detail in Section 5. Section 6 discusses the implications of our results for assessing signatures of warming-related impacts on precipitation.

\section{Models, Data Sets, and Methodology}

[6] We analyze 20th and 21st century A1B scenario precipitation data simulated by 24 global climate models archived in the CMIP3 database and featured in the Fourth Assessment Report (AR4) of the Intergovernmental Panel on Climate Change (IPCC) [Meehl et al., 2007]. The models and simulations are discussed at length in the 2007 IPCC report and the extensive peer-reviewed literature referenced therein. The particular models analyzed are identical to those analyzed in Biasutti et al. [2009] and are labeled similarly (see model abbreviations in Figure 2).

[7] We also analyze the gridded monthly mean rainfall data from three precipitation data sets for the 30-year period spanning January 1979-December 2008: (1) the January 2010 release of the NOAA Center for Climate Prediction (CPC) Merged Analysis of Precipitation (CMAP) [Xie and Arkin, 1997] product; (2) the NASA Global Climatology Precipitation Project (GPCP) [Adler et al., 2003; Huffman et al., 2009] version 2.1 product; and (3) the University of East Anglia (UEA) Climate Research Unit (CRU) [Mitchell and Jones, 2005] TS3p1 product. (For simplicity, we use the notation Year1:Year2 to denote the period of January of Year1 through December of Year2.) The $2.5^{\circ} \times 2.5^{\circ} \mathrm{CMAP}$ and GPCP products each combine satellite and rain gauge measurements from a variety of sources; the $0.5^{\circ} \times 0.5^{\circ} \mathrm{CRU}$ product, regridded here to $2.5^{\circ} \times 2.5^{\circ}$ by simple area-weighting of available grid points, comprises gauge measurements only. Each data set was downloaded from the International Research Institute/Lamont-Doherty Earth Observatory data library (http://iridl.ldeo.columbia. edu/index.html). 


\section{$2075: 2099-1975: 1999$}

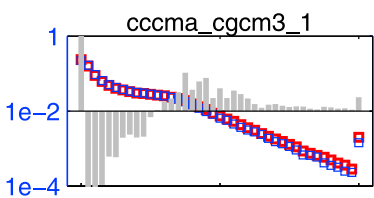

gfdl_cm2_0
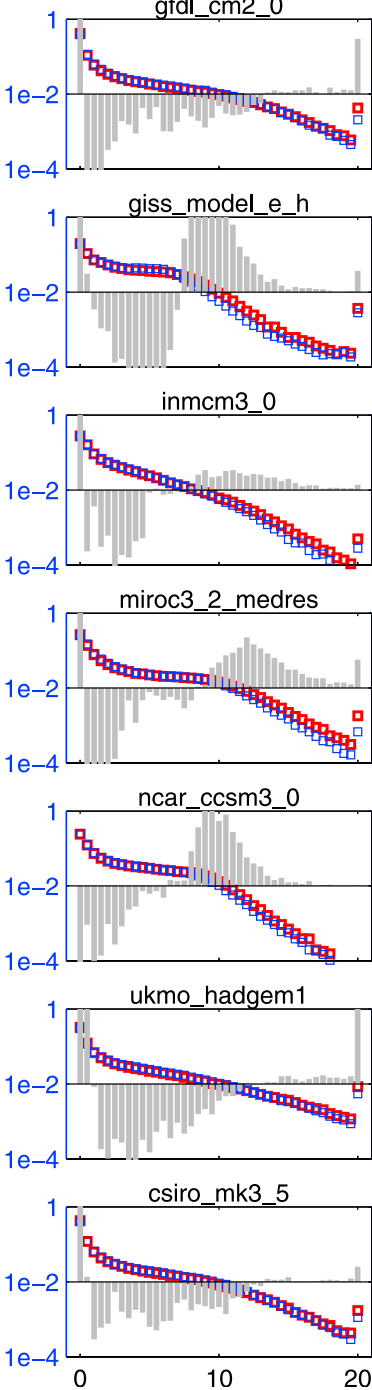

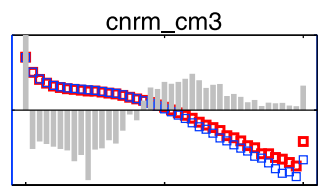

gfdl_cm2_1

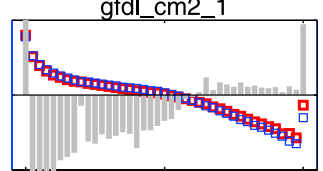

giss model e $r$

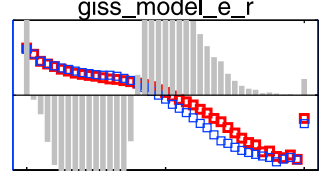

ips|_cm4

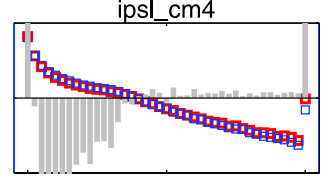

mpi_echam5

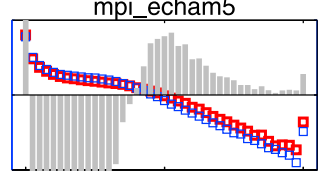

ncar_pcm1

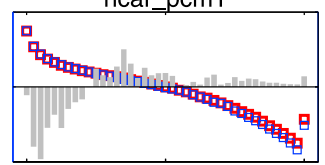

bccr_bcm2_0

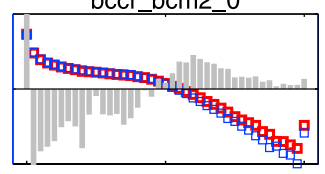

miub_echo_g

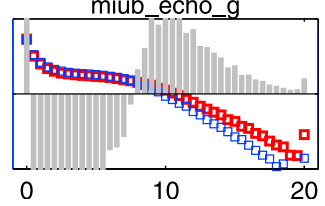

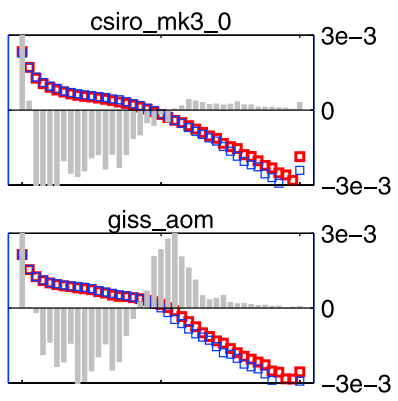
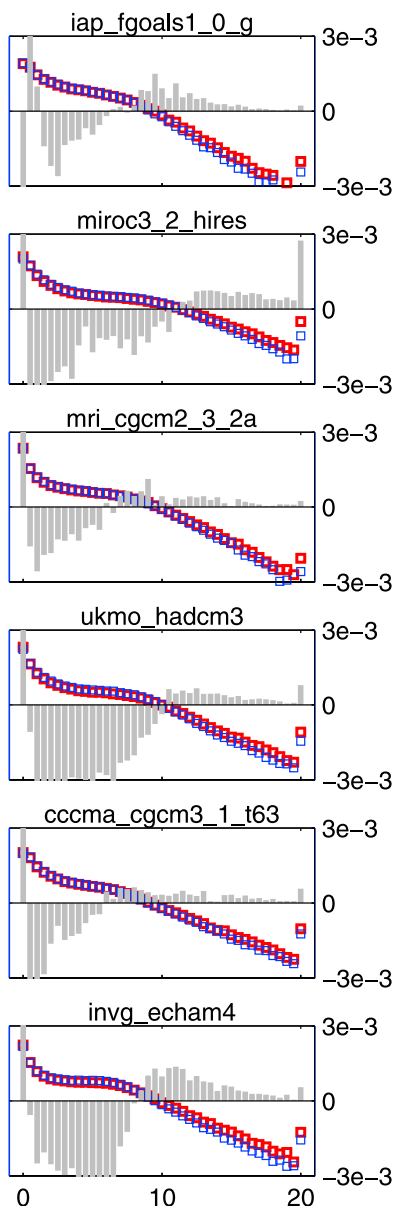

Figure 2. Ends of the 20th and 21st century precipitation histograms for the 24 CMIP3 models. Depicted here for each of the 24 models are monthly mean tropical land region precipitation histograms for the periods 1975:1999 (blue squares) and 2075:2099 periods (red squares, respectively; relative to the logarithmic vertical axis on the left), as well as the difference histogram (dark gray bars; relative to the vertical axis on the right). Note that the values in the rightmost bins include all counts above $20 \mathrm{~mm}$ day $^{-1}$.

[8] Our focus here is restricted to land grid points, given the obvious implications of land region precipitation for human impacts. For the purposes of comparison to observations, there are also data considerations, such as the availability of rain gauge measurements and concerns about the fidelity of satellite-derived trends over the ocean given that both IR and microwave satellite data infer precipitation from cloud characteristics rather than directly measuring rainfall [Adler et al., 2000]. Well-known model deficiencies that may impact the high-frequency statistics (e.g., lack of mesoscale organization) likely affect the monthly statistics, but we expect monthly values to be less sensitive than daily values.

\section{CMIP3 Results for Late-21st Minus Late-20th Centuries}

[9] Figure 1 depicts normalized histograms of tropical land region monthly mean precipitation rates for the ensemble mean of the 24 CMIP3 models for the late 20th 

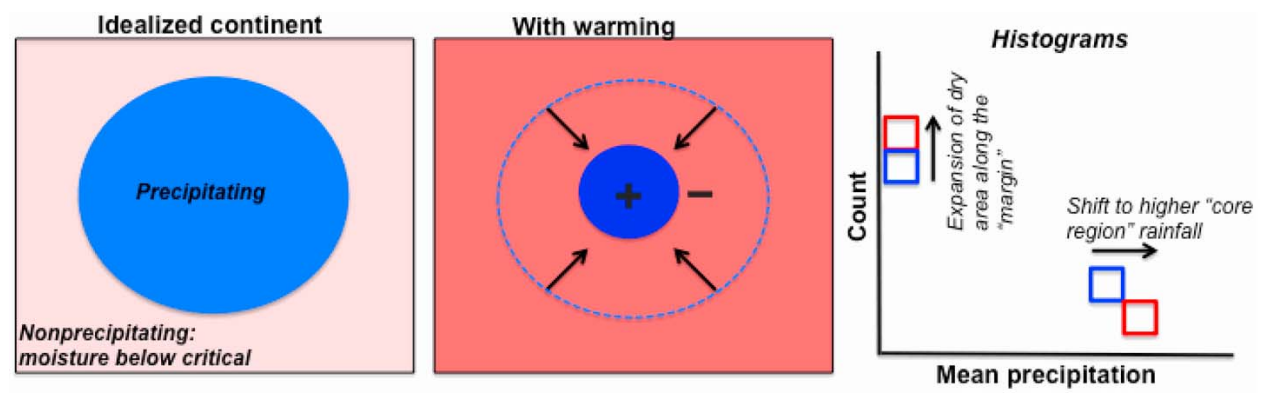

Figure 3. The impact of tropospheric warming on tropical precipitation histograms from the convective margins prototype of Lintner and Neelin [2007]. The spatial distribution of precipitation for an idealized continent under (left) normal and (middle) warmed conditions, respectively. (right) The histograms indicate how the bimodal count distribution changes between the normal (blue) and warmed (red) states. See text for discussion.

(1975:1999; blue squares) and late 21st (2075:2099; red squares) centuries. Figure 2 depicts similar histograms for each of the 24 models; note that the values plotted in rightmost bins in Figure 2 encompass all counts above $20 \mathrm{~mm} \mathrm{day}^{-1}$. Consistent with the observed monthly tropical precipitation distribution (see Figure 5 below), the model-simulated histograms exhibit highly non-Gaussian statistics, with prominent positive skewness and kurtosis (leptokurtosis). In the late-20th-period, roughly one third of all tropical land region monthly means fall into the $0-0.5 \mathrm{~mm}$ day $^{-1}$ bin. For bins above $\sim 8 \mathrm{~mm} \mathrm{day}^{-1}$, the counts decrease approximately exponentially, i.e., linearly according to the logarithmic scale used in Figure 1. For daily precipitation data, prior studies have fitted histograms with gamma distributions [Husak et al., 2007]; however, it is not obvious how monthly distributions should relate to such distributions.

[10] For our change metric, we subtract the late-20th century histograms from the late-21st century histograms (gray bars in Figures 1 and 2). Differencing the histograms shows a clear increase in ensemble-mean counts in the lowest bin $\left(0-0.5 \mathrm{~mm} \mathrm{day}{ }^{-1}\right)$ as well as in those bins for which precipitation exceeds $\sim 7 \mathrm{~mm}$ day $^{-1}$, although the $1 \sigma$ spread, as shown by the horizontal lines in Figure 1, excludes zero only for precipitation bins above $\sim 12 \mathrm{~mm}$ day $^{-1}$. Amplification of both histogram extremes implies increasing incidence of both very wet and very dry monthly mean rainfall rates under late 21 st century conditions. Many of the individual models manifest qualitatively similar histogram differences (Figure 2), although there are notable intermodal differences in the quantitative characteristics such as the precipitation value at which positive difference tails emerge on the high side of the precipitation range. Several of the models also have negative differences in the $0-0.5 \mathrm{~mm}$ day $^{-1}$ bin.

[11] The differences in the precipitation histogram over tropical land areas between the late-20th and late-21st centuries broadly reflect intensification of the "atmospheric branch" of the tropical hydrologic cycle through sharpening of the contrast between wet and dry conditions [Held and Soden, 2006; Allan et al., 2010]. While this interpretation is not new, we attempt here to provide a semiquantitative assessment of its applicability to the monthly precipitation histograms. To do so, we note that Lintner and Neelin [2007,
2008, 2009] describe conditions occurring over tropical continents (i.e., low-level inflow from a nonconvecting ocean region) for which an increase in temperature increases both the areal extent of non-precipitating conditions as well as the intensity of precipitation within strongly convecting regions. (This model unifies the upped ante and rich-getricher mechanisms of Neelin et al. [2003].) In an aggregate sense, we suggest that this model accounts for the increasing incidence of wet and dry months in a warming troposphere.

[12] Under the assumption of a transition to strong convection occurring above a (temperature-dependent) moisture threshold, $q_{c}$ [Peters and Neelin, 2006], Lintner and Neelin [2008] show that the maximum "convective core region" precipitation rate $P_{\max }$ is given by:

$$
P_{\max } \approx \frac{M q_{c} R_{\text {clear }}+M_{c} E}{M_{c}+f_{c r f} M q_{c}} ; q>q_{c}
$$

where $R_{\text {clear }}$ is the clear-sky radiative forcing; $E$ evaporation; $f_{c r f}$ net cloud-radiative feedback factor (related to the fraction of convective cloudiness); $M q_{c}=M_{q p} q_{c}$ is the moisture stratification with $M_{q p}$ representing the change in moisture with pressure; and $M_{c}$ is the convecting region gross moist stability. On the other hand, the transition point between nonconvecting and convecting conditions, $x_{c}$, defined along an inflow coordinate $x$ relative to an inflow point $(x=0)$, is:

$$
x_{c}=\lambda^{-1} \ln \left(\frac{q_{c}}{q_{0}}\right)
$$

where the length-scale $\lambda^{-1}$ is related to the ratio of moistening by flow convergence (or evaporation) and drying by advection and $q_{0}$ is the initial ("inflow") moisture value. In the context of the distribution changes under increasing tropospheric temperature, equation (1) suggests increasing $P_{\max }$ by increasing $q_{c}$, implying a shift of the high-side of the histogram to the right; while equation (2) suggests increasing $x_{c}$, implying an increase in the occupation of the lowest bin.

[13] Figure 3 provides a schematic summary of the changes implied by equations (1) and (2) for an idealized tropical continent and the associated frequency histogram. In the base state (Figure 3, left), an idealized tropical continent is depicted with a single interior convecting region. If the 


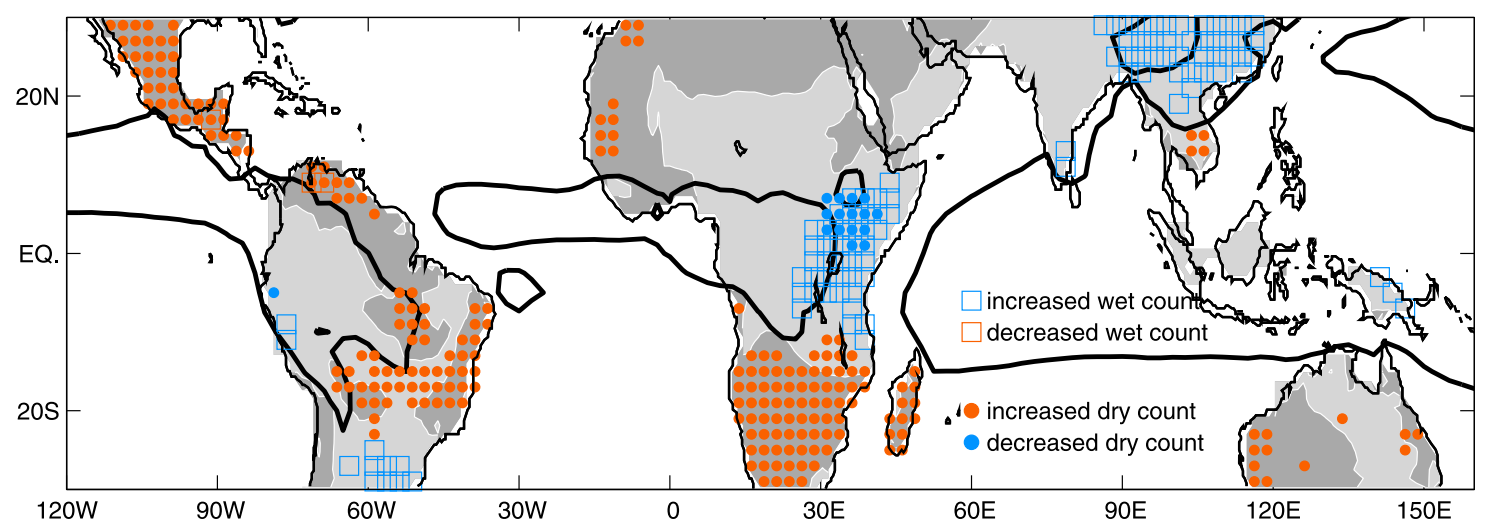

Figure 4. Map view of the changes in the precipitation distribution extremes for the late 21st - late 20th century in the CMIP3 models. Depicted are grid points contributing to the 2075:2099-1975:1999 CMIP3 model differences in the either the $0-0.5 \mathrm{~mm}^{-1 a y}{ }^{-1}$ bin ("dry counts"; circles) or the sum of all bins for which precipitation $>6 \mathrm{~mm}^{-1}{ }^{-1}$ ("wet counts"; squares). Also shown is the ensemble-mean $4 \mathrm{~mm} \mathrm{day}^{-1}$ precipitation contour as a proxy for regions of strong tropical convection (thick black line) and the sign of the ensemble-mean precipitation 2075:2099-1975:1999 difference, with light (dark) shading showing where the precipitation difference is positive (negative).

continent is characterized by large-scale convergence, the location of edge of the convection zone (i.e., $x_{c}$ ) is set by conditions along a local inflow path from a moisture source (e.g., the adjacent ocean) as in equation (2). As the continent warms (Figure 3 , middle), $q_{c}$ increases, which by equation (2) results in a larger value for $x_{c}$ for all other factors equal; thus the areal extent of the convecting region decreases. At the same time, according to equation (1), precipitation within the convecting region increases. The net change to the histogram (Figure 3, right) reflects expansion of the dry margin, so increasing counts in the lowest bin, and increasing precipitation within the convection zone, so increasing counts in the highest bin.

[14] Figure 4 depicts a map view of the late-21st minus late-20th century differences for the CMIP3 models. To reduce the noise inherent at the grid point scale, Figure 4 depicts only those grid point changes satisfying a threshold condition considering both the size of the count change at each grid point as well as the number of models for which the sign of the count difference is consistent. That is, for a grid point to be highlighted, the late 21 st minus late 20th century count difference within a given model must be $\geq 3(\leq-3)$, in which case that model is assigned a score of $1(-1)$. The sum over these scores for all 24 models is then computed: the grid points displayed in Figure 4 are those for which score sum is either greater than 12 for an increase to be displayed or less than -12 for a decrease to be displayed. We note that this threshold condition is somewhat arbitrary, although the results shown are insensitive to modest variations in the minimum count difference and score sum. Furthermore, a more sophisticated approach accounting for differences in the mean values within each bin may be more appropriate but is not necessary for our purposes here.

[15] Most of the dry count increases (brown circles) occur in regions where rainfall changes are negative. Such regionse.g., southeastern tropical South America, southern Africa, and western Australia - are climatologically dry under current climate. Almost without exception, the areas exhibiting increases in dry counts do not exhibit corresponding decreases in wet count. Indeed, decreases in wet counts that pass our criteria are almost entirely absent from tropical land areas (with the exception of northernmost South America). Further, although dry count increases do occur outside of those areas in which rainfall changes are negative, wet count increases (blue squares) occur exclusively in regions where rainfall changes are positive (southeast Asia, east Africa). In addition, some areas in which rainfall changes are positive also exhibit dry count decreases (blue circles) that pass our criteria. These are concentrated primarily in eastern Africa, and mostly correspond with areas that also exhibit wet count increases.

[16] While the spatial distribution of count differences evident in Figure 4 is broadly consistent with the simplistic model outlined above, it is clear that regional-scale effects are substantial. At some level, this doubtlessly reflects the small sample sizes at the grid point scale. More significantly, the simplistic model is based on thermodynamical understanding of the controls on behavior between distinct mean hydroclimatic regimes, namely nonconvecting and convecting regions. In reality, transitions between such regimes are not abrupt and may be controlled by factors not accounted for in the model, e.g., dynamical changes associated with the feedback between a change in convection and circulation or land-atmosphere coupling. Moreover, the simplistic model assumes a steady state equilibrium, while extreme eventswith events here understood as anomalous monthly mean precipitation values - are frequently linked to particular episodic conditions. However, we suggest that the model nonetheless provides a useful thermodynamic framework for interpreting changes in the likelihood of episodic monthly mean extreme behavior at different mean hydroclimatic conditions.

\section{Late 20th Century Observations and CMIP3 Models}

[17] Given the response of the precipitation distribution to the elevated radiative forcing projected for the late-21st 
a) CMAP

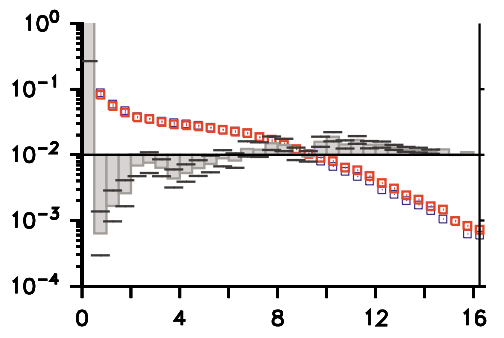

b) GPCP

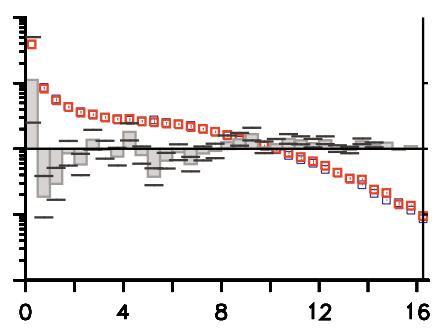

c) $\mathrm{CRU}$

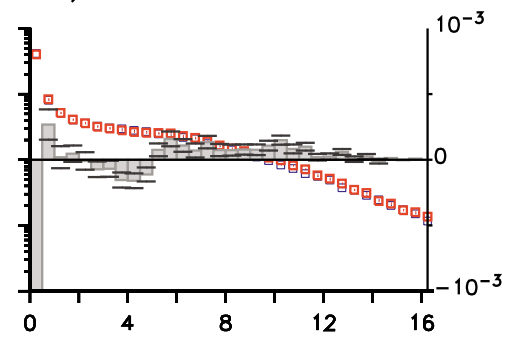

Figure 5. Observed precipitation histograms and their differences over the period 1979-2008. As in Figure 1 but for 15 year subintervals 1979:1993 and 1994:2008 for the (a) CMAP; (b) GPCP; and (c) CRU precipitation data sets. Here the dashed lines depict the $\pm 1 \sigma$ levels as estimated from bootstrap sampling.

century, it is reasonable to ask whether the distribution amplification seen for the late-21st minus late-20th century histograms is already emerging in response to the global warming that has occurred over recent decades. Given that the tropical troposphere has warmed by $\sim 0.1 \mathrm{~K} /$ decade over the past 30 years [Santer et al., 2005], we calculate precipitation histograms and their differences for the two 15-year periods covering 1979:1993 and 1994:2008 from the CMAP, GPCP, and CRU data sets (Figure 5). Here we have used bootstrap sampling with replacement to generate 1000 sample histogram differences, from which $\pm 1 \sigma$ levels for are estimated. As with the simulated data, in each of observational data sets, roughly $35 \%$ of all tropical land region monthly means fall into the bin between 0 and $0.5 \mathrm{~mm}_{\text {day }}{ }^{-1}$. There is also a log linear regime at high precipitation $\left(>\sim 8 \mathrm{~mm} \mathrm{day}^{-1}\right)$, although the slopes differ slightly among the three data sets.

[18] When comparing the later observational period (1994:2008) with the earlier observational period (1979:1993), the CMAP data set, and (to a lesser extent) the GPCP data set, show increases both in the very high monthly precipitation bins $\left(>6 \mathrm{~mm} \mathrm{day}^{-1}\right)$ and in the lowest precipitation bin $\left(<0.5 \mathrm{~mm} \mathrm{day}^{-1}\right)$ between 1979:1993 and 1994:2008 (Figure 5, gray bars). These observed differences in the monthly scale distribution are consistent with the analysis of binned annual-mean precipitation trends over recent decades by Lau and $W u$ [2007], which showed decreasing annualmeans over the lowest 5 th percentile and increasing annualmeans over highest 10th percentile during recent decades. Furthermore, the behavior of the CMAP and GPCP difference histograms is broadly consistent with the changes simulated by the CMIP3 ensemble for the late-21st minus late-20th centuries (Figure 1), and for the two periods of the late-20th century (1979:1993 and 1994:2008) (Figure 6). For the recent decades in the CMIP3 models, it is important to note that although the ensemble-mean signal does manifest the pattern of positive/negative/positive differences for the lowest/intermediate/and high precipitation bins, the signal lies within the intraensemble spread across the range of precipitation values shown. Examination of the individual model histograms (Figure 7) suggests that only half exhibit differences that are qualitatively consistent with the ensemble-mean, and even then, the quantitative details differ considerably across the models.

[19] The difference histogram for the CRU data set (Figure 5c) is somewhat at odds with the CMAP and GPCP difference histograms. While the CRU data exhibit increased counts in the high precipitation bins during 1994:2008, the difference for the lowest bin is negative, indicating decreasing counts of the lowest monthly mean precipitation values during the later period. This disagreement for the lowest bin counts suggests caution in assessing the robustness of the observational results.

[20] In interpreting these results, we caution that the observational data sets have known strengths and weaknesses and further exhibit systematic differences in data coverage. While land region precipitation estimates in CMAP and GPCP show widespread agreement, substantial regional discrepancies, such as over equatorial West Africa, do occur [Yin et al., 2004]. Since the CRU data comprise rain gauges only, these may substantially undersample the tropics where coverage is sparse. For example, the CMAP data suggest increasing later period dry counts over eastern tropical South America (see Figure 4 and associated discussion), but CRU has relatively sparse coverage in that region. On the other hand, CRU shows a large increase in dry counts over Africa (not shown), although station data there are generally considered poor. A further caveat is that the spatiotemporal heterogeneity of the rain gauge data, as

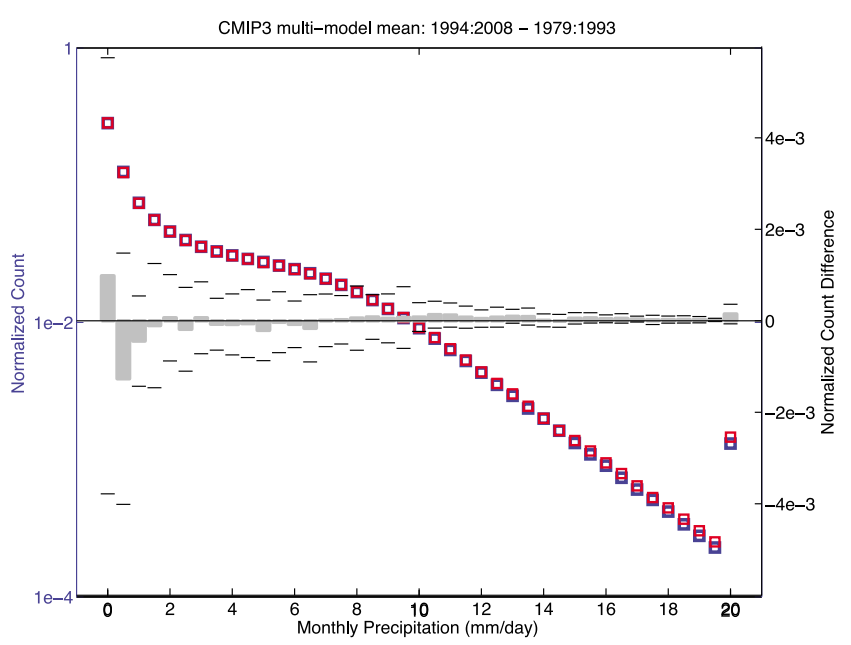

Figure 6. Ensemble-mean CMIP3 precipitation histograms and their differences over the period 1979-2008. As in Figure 1 but for 15 year subintervals 1979:1993 and 1994:2008. 
1994:2008 - 1979:1993
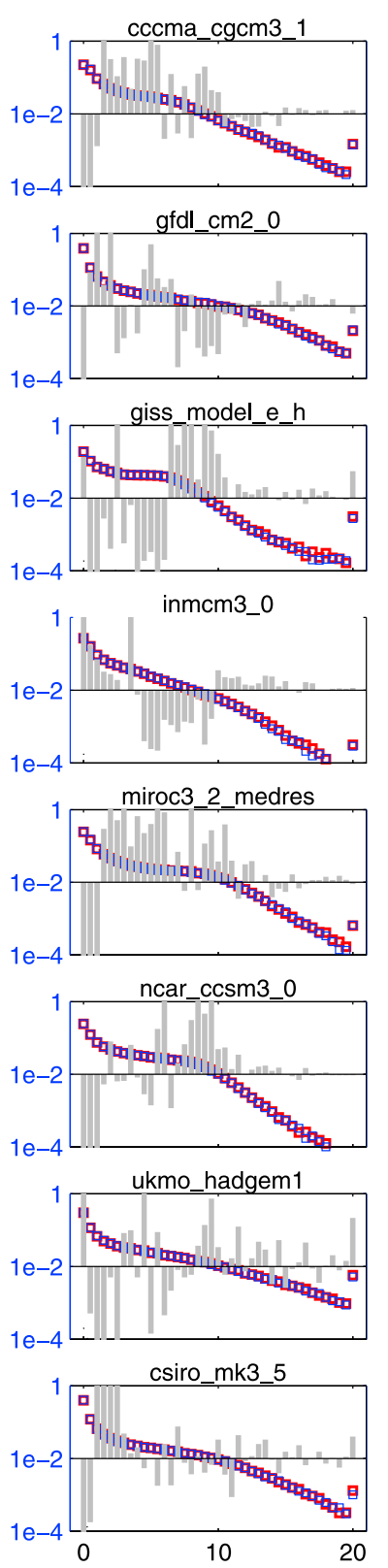

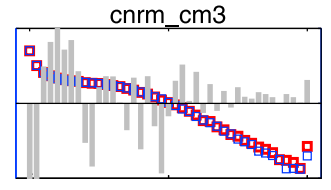

gfdl_cm2_1

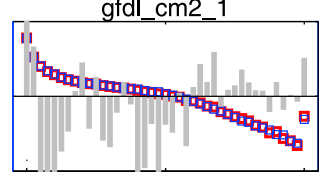

giss_model_e_r

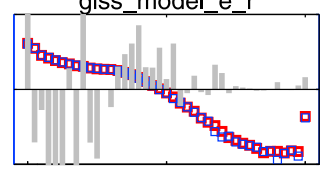

ipsl_cm4

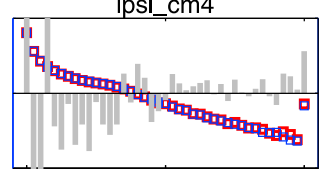

mpi_echam5

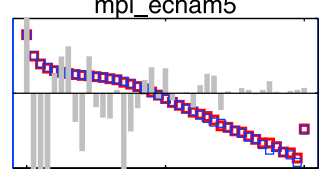

ncar_pcm1

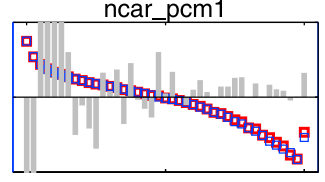

bccr_bcm2 0

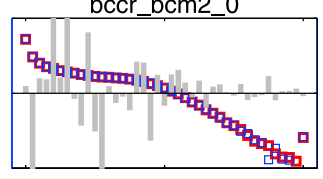

miub echo $g$

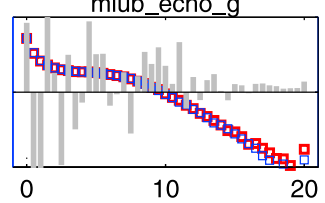

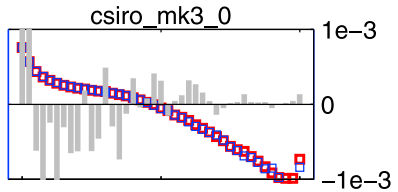
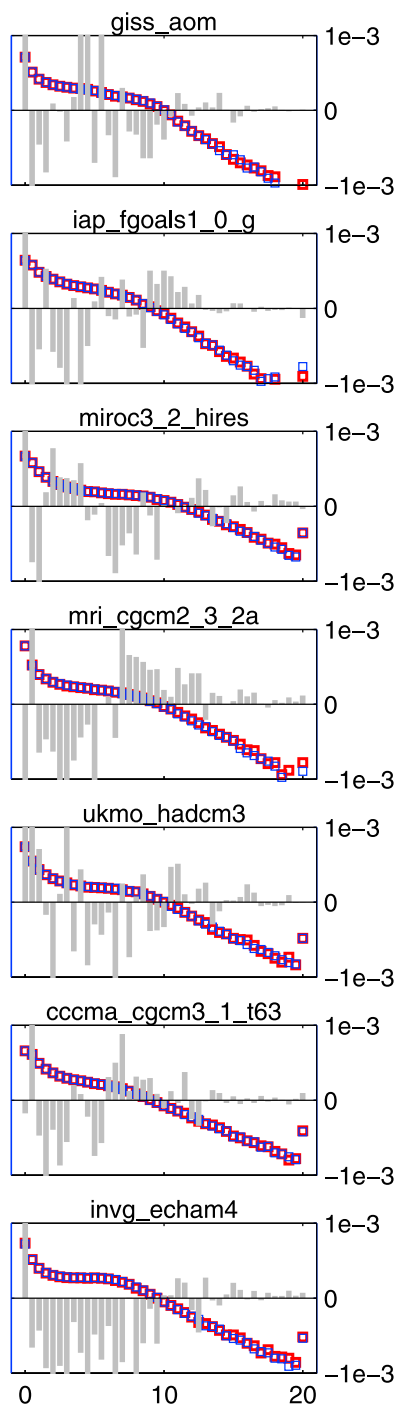

Figure 7. Late 20th century precipitation histograms for the 24 CMIP3 models. As in Figure 2 but for the 15 year subintervals 1979:1993 and 1994:2008.

well as changes in satellite observing platforms, could introduce spurious behavior; we therefore cannot exclude the possibility that the observed histogram changes reflect such data artifacts.

\section{Precipitation Histograms Defined Directly in Terms of Temperature and Their Relationship to ENSO}

[21] The disagreement among the 20th century results of CMIP3 models suggests that natural ("unforced") variability may have an important impact on the precipitation statistics. Indeed, the simulated late-20th-century tropical warming is an order of magnitude smaller than the simulated late-21stcentury tropical warming (Figure 8), suggesting that the signature response that we identify in the late-21st-century simulations should be much less robust in response to the more slight warming that has occurred over the recent decades. We further note that large-scale land use change such as deforestation or agricultural conversion may potentially amplify extremes over tropical land regions [Lee et al., 2011].

[22] In order to isolate the influence of warming, we construct histograms obtained by sorting the precipitation data directly on tropical tropospheric temperature anomalies, rather than chronologically. To do this, we sort the CMAP 


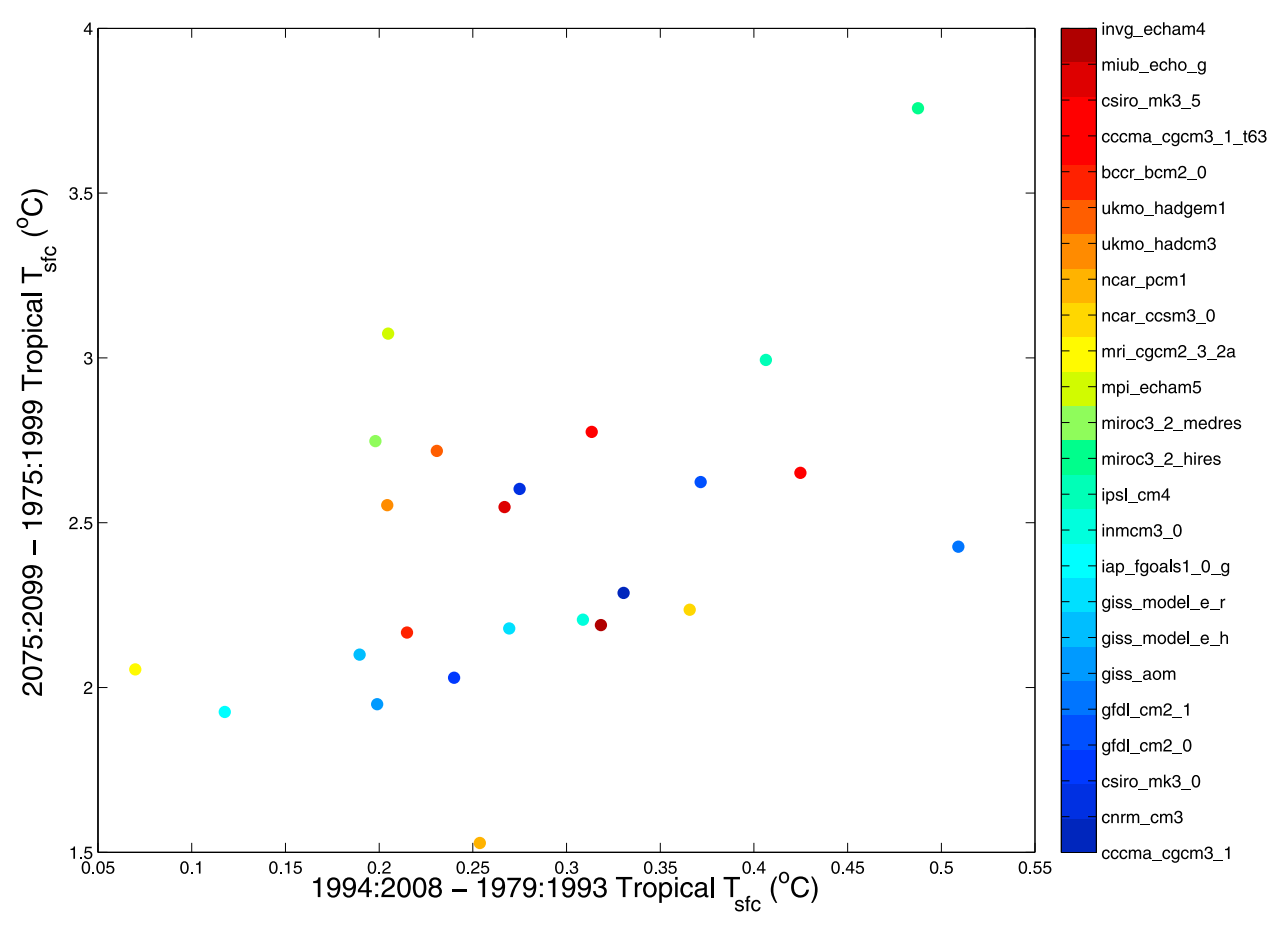

Figure 8. Comparison of CMIP3 simulated surface temperature differences for 1979:1993 and 1994:2008 ( $x$ axis) and 1975:1999 and 2075:2099 ( $y$ axis).

data by dividing the monthly stratified values for 1979 to 2008 into the 15 warmest and 15 coolest Januaries, Februaries, ..., Decembers, using deep-layer $(850 \mathrm{mb}-200 \mathrm{mb})$ tropospheric temperature anomalies estimated from the NCEP/NCAR Reanalysis 1 to identify the warmest and coolest months (Figure 9). Note that broadly comparable results are obtained from temperature-sorting the GPCP and CRU data and are not discussed here.

[23] Overall, the temperature-sorted CMAP differences (Figure 9b) are smaller than the chronological sorting (Figure 9a): in fact, only the "warm minus cool" increase in counts in the $0-0.5 \mathrm{~mm}^{-1 a y}{ }^{-1}$ bin exceeds the $1 \sigma$ level from the bootstrap uncertainty estimate. At first glance, this appears to contradict the hypothesis of tropospheric warming as the source of the decadal histogram change. However, we note that presence of several sizable El Niño events during the last 3 decades (e.g., 1982/83, 1986/87, and 1997/ 98) may influence the temperature-based analysis. Although
El Niño events lead to widespread warming of the tropical troposphere, the spatially non-uniform way in which ENSO forcing interacts with tropical circulation leads to different spatial rearrangement of tropical rainfall [Ding and Wang, 2005]. For example, using idealized model simulations with greenhouse gas forcing tuned to match temperature increases during an El Niño event, Lintner and Chiang [2005] showed that while both greenhouse warming and El Niño decrease rainfall in tropical areas of low climatological mean precipitation, they oppose each other in areas of higher mean climatological precipitation, i.e., El Niño decreases rainfall but greenhouse gas warming increases it.

[24] In order to isolate the influence of ENSO on the 20thcentury histograms, we construct histograms by sorting on temperature after first regressing out the ENSO signature, with the latter reflected in the NINO3 region sea surface temperature index. Removing the ENSO signature is found to yield a "warm minus cool" difference signature (Figure 9c) a) CMAP-year sorted

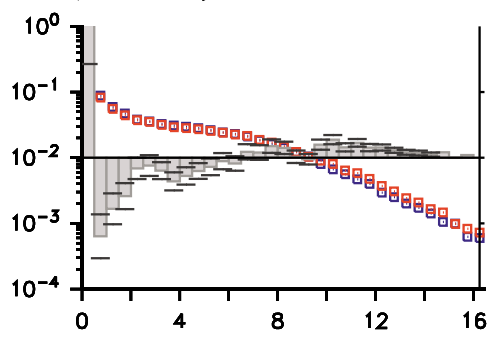

b) CMAP-T sorted

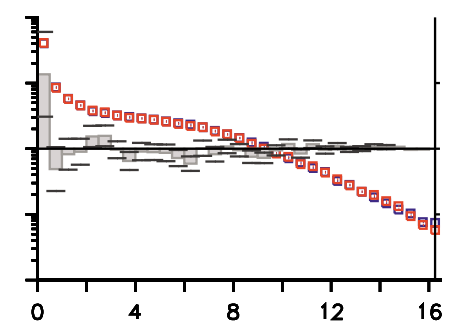

c) CMAP-T sorted (no ENSO)

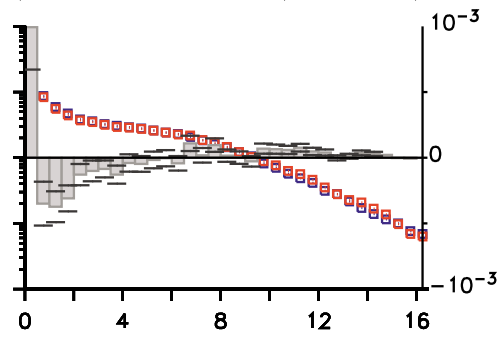

Figure 9. CMAP histograms computed directly from temperature. (a) The chronologically sorted histogram (Figure 5a). (b) Temperature-sorted histograms, using the 15 warmest (red squares) and coolest (blue squares) Januaries, Februaries, ..., Decembers over 1979-2008. (c) Temperature-sorted histograms but using NINO3-regressed temperature anomalies. 
a) GFDL-year sorted

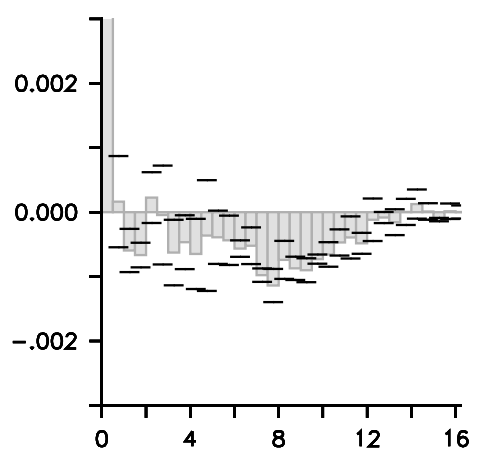

b) GFDL-T sorted

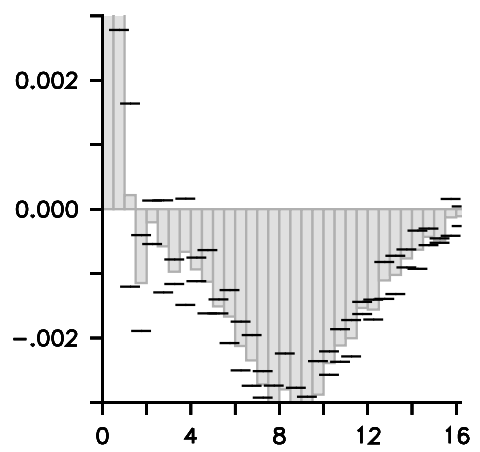

c) GFDL-T sorted (no ENSO)

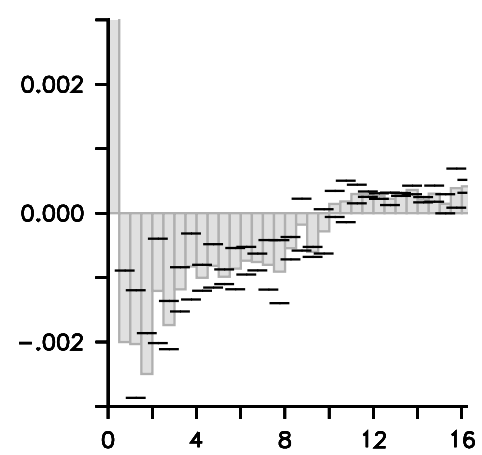

Figure 10. GFDL CM2.1 histograms computed directly from temperature. As in Figure 9, but for the period 1860-1999 in a 3-member ensemble of the GFDL model.

that is comparable to that found in the chronological sorting (Figure 9a), suggesting that ENSO teleconnections do indeed confound the direct effects of atmospheric warming on the observed monthly distribution of tropical precipitation. Of course, the regression approach used here may not provide the cleanest separation of anthropogenic warming from ENSO; given a longer time series, one could envision excluding large ENSO events directly.

[25] In fact, we obtained qualitatively similar behavior for such a temperature-based analysis for a 3-member ensemble of GFDL CM2.1 integrated over the 1860-1999 period (Figure 10), with the longer data set affording a greater temperature contrast than exists in the shorter observational records. The chronological difference of 1985:1999 and 1860:1874 (Figure 10a) underscores the tendency for the later-period GFDL precipitation counts to increase in the nearest-to-zero bin but to decrease broadly over the remaining bins. Sorting by temperature (Figure 10b) yields much larger negative differences, especially in the range of 8$10 \mathrm{~mm} \mathrm{day}^{-1}$. By contrast, sorting on temperature after the NINO3 variability has been removed (Figure 10c) results in increased warm month counts beyond $\sim 10 \mathrm{~mm} \mathrm{day}^{-1}$, in agreement with the changes seen in the late-21st-century CMIP3 simulations. That the removal of ENSO variability changes the sign of the response for warm minus cool conditions in the highest precipitation bins in the GFDL model suggests that ENSO may indeed complicate the simulated response of the wet tail to elevated greenhouse forcing, at least when the warming forced by greenhouse gases remains small. Precisely how this interaction plays out in other models (not to mention the observations) is worth investigating in greater detail, as it likely depends on the detailed expression of the ENSO teleconnection over tropical land regions.

\section{Summary and Conclusions}

[26] In this study, we document changes in histograms of monthly mean tropical land region rainfall for 24 CMIP3 simulations of greenhouse-gas-induced global warming. The ensemble-mean histogram between the late-21st and late20th centuries manifests increasing incidence of both the lowest $\left(0-0.5 \mathrm{~mm}\right.$ day $\left.^{-1}\right)$ and very high monthly mean precipitation rates, with widespread consistency among the model simulations. Thus, the bulk tropics-wide histogram of monthly mean precipitation rates appears to reflect a distinct signature of global warming.

[27] We reiterate that the changes in precipitation distribution seen in the late-21st-century simulations should not be interpreted too strictly in terms of the theoretical arguments posited for daily (or sub-daily) time scales, as these might suggest that any one location should experience both an increase in the intensity of rain events and more frequent and/or lengthier dry episodes in a warmer world [e.g., Giorgi et al., 2011]. In particular, since Figure 4 shows that wet anomalies in wet regions are mostly responsible for the increase in high-rainfall counts and dry anomalies in dry regions are mostly responsible for the increase in very low rainfall counts, we posit that our results reflect increased rainfall spatial gradients within the tropics.

[28] The warming that has occurred over the tropics in recent decades raises the question of whether the increasing counts of the wet and dry tails of the precipitation distribution may in fact be evident in observed precipitation. We thus analyze changes in the precipitation distributions for two 15-year subperiods of the 1979-2008 interval using three observed precipitation products. While the CMAP and (to a lesser extent) GPCP products hint at similar signatures, the CRU product fails to show an increase in counts in the lowest $\left(0-0.5 \mathrm{~mm}\right.$ day $\left.^{-1}\right)$ bin. At this stage, we cannot distinguish whether the observed changes in the bulk precipitation histograms point to an emerging signal from global warming or are the effect of the regional rainfall changes associated with ENSO; in both cases, they are linked to precipitation changes that enhance mean moisture gradients across tropical land regions. Analysis of the CMIP3 models over the same late-20th century subperiod reveals only a weak signature in the ensemble-mean histogram difference, further highlighting the dual influences of anthropogenic warming and natural variability on the wet and dry tails of the monthly precipitation distribution over the last 30 years. In isolating the influence of atmospheric warming from the influence of ENSO teleconnections, we find that ENSO variability does indeed confound the effects of atmospheric warming on the distribution of tropical land precipitation, particularly at the wet tail, where atmospheric warming leads to increasing counts but El Niño events lead to decreasing counts.

[29] The opposing effects of ENSO variability and atmospheric warming raise a number of questions, including (1) 
what is the minimum level of greenhouse forcing that is necessary for the signature seen in the late-21st century CMIP3 simulations to emerge beyond the background influence of ENSO, and (2) how do changes in ENSO variability that are induced by anthropogenic radiative forcing influence the response of the tropical precipitation distribution to global warming, particularly given uncertainties about the ENSO response [e.g., IPCC, 2007, chapter 10, Figure 10.16; Vecchi and Soden, 2007]. These questions are clearly intertwined, and highlight the importance of improving our understanding of the response of both precipitation processes and ENSO to elevated greenhouse forcing.

[30] Acknowledgments. B.R.L. and M.B. contributed equally to this work. We thank the British Atmospheric Data Centre for providing access to the CRU data and thank Anthony DeAngelis for useful comments on the text. We acknowledge the modeling groups, the Program for Climate Model Diagnosis and Intercomparison (PCMDI) and the WCRP's Working Group on Coupled Modeling (WGCM) for their roles in making available the WCRP CMIP3 multimodel data set. Support for this data set is provided by the Office of Science, U.S. Department of Energy. Our work was supported by NSF AGS-1103209 and New Jersey Agricultural Experiment Station Hatch grant NJ07102. N.S.D. acknowledges support from DOE's program in Integrated Assessment of Global Climate Change. J.-E.L. acknowledges that part of the research was carried out at the Jet Propulsion Laboratory, California Institute of Technology, under a contract with the National Aeronautics and Space Administration.

\section{References}

Adler, R. F., G. J. Huffman, D. T. Bolvin, S. Curtis, and E. J. Nelkin (2000), Tropical rainfall distributions determined using TRMM combined with other satellite and rain gauge information, J. Appl. Meteorol., 39, 2007-2023, doi:10.1175/1520-0450(2001)040<2007:TRDDUT>2.0.CO;2.

Adler, R. F., et al. (2003), The Version-2 Global Precipitation Climatology Project (GPCP) monthly precipitation analysis (1979-Present), $J$. Hydrometeorol., 4, 1147-1167, doi:10.1175/1525-7541(2003)004<1147: TVGPCP $>2.0 . \mathrm{CO} ; 2$.

Allan, R. P., B. J. Soden, V. O. John, W. Ingram, and P. Good (2010), Current changes in tropical precipitation, Environ. Res. Lett., 5, 025205, doi:10.1088/1748-9326/5/2/025205.

Biasutti, M., A. H. Sobel, and S. J. Camargo (2009), The role of the Sahara Low in summertime Sahel rainfall variability and change in the CMIP3 models, J. Clim., 22, 5755-5771, doi:10.1175/2009JCLI2969.1.

Ding, Q., and B. Wang (2005), Circumglobal teleconnection in the northern hemisphere summer, J. Clim., 18, 3483-3505, doi:10.1175/JCLI3473.1.

Emori, S., and S. J. Brown (2005), Dynamic and thermodynamic changes in mean and extreme precipitation under changed climate, Geophys. Res. Lett., 32, L17706, doi:10.1029/2005GL023272.

Giorgi, F., E. Coppola, E. S. Im, N. S. Diffenbaugh, X. Gao, and Y. Shi (2011), Higher hydroclimatic intensity with global warming, J. Clim., 24, 5309-5324, doi:10.1175/2011JCLI3979.1.

Held, I. M., and B. J. Soden (2006), Robust response of the hydrological cycle to global warming, J. Clim., 19, 5686-5699, doi:10.1175/ JCLI3990.1.

Huffman, G. J., R. F. Adler, D. T. Bolvin, and G. Gu (2009), Improving the global precipitation record: GPCP Version 2.1, Geophys. Res. Lett., 36, L17808, doi:10.1029/2009GL040000.
Husak, G. J., J. Michaelson, and C. Funk (2007), Use of the gamma distribution to represent monthly rainfall in Africa for drought monitoring applications, Int. J. Climatol., 27, 935-944, doi:10.1002/joc.1441.

Intergovernmental Panel on Climate (2007), Change Climate Change: 2007, edited by S. Solomon et al., 996 pp., Cambridge Univ. Press, New York.

Lau, K.-M., and H.-T. Wu (2007), Detecting trends in tropical rainfall characteristics, 1979-2003, Int. J. Climatol., 27, 979-988, doi:10.1002/ joc. 1454 .

Lee, J.-E., B. R. Lintner, C. K. Boyce, and P. J. Lawrence (2011), Land use change exacerbates tropical South American drought by sea surface temperature variability, Geophys. Res. Lett., 38, L19706, doi:10.1029/ 2011 GL049066.

Lintner, B. R., and J. C. H. Chiang (2005), Reorganization of tropical climate during El Niño: A weak temperature gradient approach, J. Clim., 18, 5312-5329, doi:10.1175/JCLI3580.1.

Lintner, B. R., and J. D. Neelin (2007), A prototype for convective margin shifts, Geophys. Res. Lett., 34, L05812, doi:10.1029/2006GL027305.

Lintner, B. R., and J. D. Neelin (2008), Eastern margin variability of the South Pacific Convergence Zone, Geophys. Res. Lett., 35, L16701, doi:10.1029/2008GL034298.

Lintner, B. R., and J. D. Neelin (2009), Soil moisture impacts on convective margins, J. Hydrometeorol., 10, 1026-1039, doi:10.1175/2009JHM1094.1.

Meehl, G., et al. (2007), The WCRP CMIP3 multimodel dataset: A new era in climate change research, Bull. Am. Meteorol. Soc., 88, 1383-1394, doi:10.1175/BAMS-88-9-1383.

Mitchell, T. D., and P. D. Jones (2005), An improved method of constructing a database of monthly climate observations and associated high-resolution grids, Int. J. Climatol., 25, 693-712, doi:10.1002/joc.1181.

Neelin, J. D., C. Chou, and H. Su (2003), Tropical drought regions in global warming and El Niño teleconnections, Geophys. Res. Lett., 30(24), 2275, doi:10.1029/2003GL018625.

Neelin, J. D., M. Munnich, H. Su, J. Meyerson, and C. Holloway (2006), Tropical drying trends in global warming models and observations, Proc. Natl. Acad. Sci. U. S. A., 103, 6110-6115, doi:10.1073/pnas.0601798103.

Neelin, J. D., O. Peters, J. W.-B. Lin, K. Hales, and C. E. Holloway (2008), Rethinking convective quasi-equilibrium: Observational constraints for stochastic convective schemes in climate models, Philos. Trans. R. Soc. $A$, 366, 2579-2602, doi:10.1098/rsta.2008.0056.

O'Gorman, P. A., and T. Schneider (2009), Scaling of precipitation extremes over a wide range of climates simulated with an idealized GCM, J. Clim., 22, 5676-5685, doi:10.1175/2009JCLI2701.1.

Peters, O., and J. D. Neelin (2006), Critical phenomena in atmospheric precipitation, Nat. Phys., 2, 393-396, doi:10.1038/nphys314.

Romps, D. M. (2011), Response of tropical precipitation to global warming, J. Atmos. Sci., 68, 123-138, doi:10.1175/2010JAS3542.1.

Santer, B. D., et al. (2005), Amplification of surface temperature trends and variability in the tropical atmosphere, Science, 309, 1551-1556, doi:10.1126/science.1114867.

Solomon, S., G.-K. Plattner, R. Knutti, and P. Friedlingstein (2009), Irreversible climate change due to carbon dioxide emissions, Proc. Natl. Acad. Sci. U. S. A., 106, 1704-1709, doi:10.1073/pnas.0812721106.

Vecchi, G. A., and B. J. Soden (2007), Global warming and the weakening of the tropical circulations, J. Clim., 20, 4316-4340, doi:10.1175/ JCLI4258.1.

Xie, P., and P. A. Arkin (1997), Global precipitation: A 17-year monthly analysis based on gauge observations, satellite estimates, and numerical model outputs, Bull. Am. Meteorol. Soc., 78, 2539-2558, doi:10.1175/ 1520-0477(1997)078<2539:GPAYMA $>2.0$.CO;2.

Yin, X. G., A. Gruber, and P. Arkin (2004), Comparison of the GPCP and CMAP merged gauge-satellite monthly precipitation products for the period 1979-2001, J. Hydrometeorol., 5, 1207-1222, doi:10.1175/ JHM-392.1. 